\title{
PUBLICAÇÕES DO PROFESSOR NELSON DA NÓBREGA FERNANDES
}

\section{Artigos Publicados}

1. Fernandes, Nelson da Nobrega. O conceito carioca de subúrbio: um rapto ideológico. Revista da FAU UFRJ, v. 2, p. 8-15, 2010.

2. Fernandes, Nelson da Nobrega; Oliveira, Alfredo C. T. Marechal Hermes e as (des) conhecidas origens da habitação social no Brasil: o paradoxo da vitrine não-vista. Scripta Nova (Barcelona), v. XIV, p. 81, 2010.

3. Fernandes, Nelson da Nobrega. Capitalismo e morfologia urbana na longa duração. Rio de Janeiro: séc. ( XVIII-XXI). Scripta Nova (Barcelona), v. XII, p. 16, 2008.

4. Fernandes, Nelson da Nobrega. Os militares e o espaço urbano do Rio de Janeiro: um programa de pesquisa em geografia urbana e geografia política. Scripta Nova (Barcelona), v. X, p. 218-227, 2006.

5. Fernandes, Nelson da Nobrega e Menezes, Maria Lucia Pires. As capitais do Acre: A cidade e os poderes. Scripta Nova (Barcelona), Barcelona, v. IX, n.194, p. 1-14, 2005.

6. Fernandes, Nelson da Nobrega. A cidade, a festa e a cultura popular. Geographia, Revista da Pós-Graduação em Geografia da UFF, Niterói, v. 6, n.11, p. 55-61, 2004.

7. Fernandes, Nelson da Nobrega. Geografia Cultural, festa e cultura popular: limites do passado e possibilidades do presente. Espaço e Cultura (UERJ), v. 15, p. 23-32, 2003.

8. Fernandes, Nelson da Nobrega. Globalización y crisis del federalismo en Brasil. Scripta Nova (Barcelona), Barcelona, v. 45, n.22, p. 01-09, 1999.

9. Fernandes, Nelson da Nobrega. La ciudad y la fiesta: Origenes, desarrollo y significado de las escolas de samba de Rio de Janeiro (19281941). Scripta Nova Revista Electronica de Geografia y Ciencias Sociales Universidad de Barcelona Nº 24, Barcelona, v. 24, p. 1-14, 1998. 
10. Fernandes, Nelson da Nobrega. Questões do federalismo no Brasil dos anos 90. Revista da Pós Graduação Em Geografia, Rio de Janeiro, v. 1, p. 49-63, 1997.

\section{Livros publicados/organizados ou edições}

1. Fernandes, Nelson da Nobrega. O rapto ideológico da categoria subúrbio: Rio de Janeiro (1858-1945). 1. ed. Rio de Janeiro: Apicuri, 2011. v. 1

2. Fernandes, Nelson da Nobrega e Oliveira, Marcio Piñon de (Org.). 150 anos de subúrbio carioca. 1. ed. Rio de Janeiro: Lamparina; EDUFF, 2010. v. $1.253 \mathrm{p}$.

3. Fernandes, Nelson da Nobrega. Escolas de Samba: Sujeitos Celebrantes e Objetos Celebrados.. 1. ed. Rio de Janeiro: Arquivo Geral da Cidade do Rio de Janeiro, 2001. v. 1. 172p.

\section{Capítulos de livros publicados}

1. Fernandes, Nelson da Nobrega. Eletrificação do sistema suburbano da Estrada de Ferro Central do Brasil e a política urbana no Rio de Janeiro. In: Horacio Capel, Vicente Casals, Domingo Cuellar. (Org.). La electricidad en las redes ferroviarias y la vida urbana: Europa y America (siglos XIX-XX) - Colección de Historia Ferroviariaa, n ${ }^{\circ} 13$. 1ed. Madrid: Fundación de los Ferrocarriles Españoles, 2012, v. 13, p. 5-20.

2. Fernandes, Nelson da Nobrega. Capitalismo e morfologia urbana na longa duração: Rio de Janeiro (Séculos XVIII-XXI). In: Jorge Luiz Barbosa; Ester Limonad. (Org.). Ordenamento territorial e ambiental. 1ed.Niterói: Ed.UFF, 2012, v., p. 1-28

3. Fernandes, Nelson da Nobrega. Elementos sobre a Geografia Urbana no Sudeste - por uma agenda nacional comum de ensino e pesquisa em Geografia Urbana. In: Elson Manoel Pereira; Leila Christina Duarte Dias. (Org.). As cidades e a urbanização no Brasil: passado, presente e futuro. 1ed.Florianópolis: Editora Insular, 2011, v., p. 348-372.

4. Fernandes, Nelson da Nobrega e Oliveira, Alfredo César Tavares de. Marechal Hermes e as (des) conhecidas origens da habitação social no Brasil: o paradoxo da vitrine não-vista. In: Marcio Pinon de Oliveira; Nelson 
da Nobrega Fernandes. (Org.). 150 anos de subúrbio. Rio de Janeiro: Lamparina, 2010, v., p

5. Fernandes, Nelson da Nobrega. Apresentação 150 anos de subúrbio carioca. In: Marcio Pinon de Oliveira; Nelson da Nobrega Fernandes. (Org.). 150 anos de subúrbio carioca. 1ed.Rio de Janeiro; Niterói: Lamparina;EDUFF, 2010, v. , p. 9-17.

6. Fernandes, Nelson da Nobrega. Escolas de samba: encontro da identidade e da sociabilidade na metrópole. In: José Aldemir de Oliveira. (Org.). Cidades Brasileiras: territorialidades, sustentabilidade e demandas sociais. Manaus: Editora da luniversidade Federal do Amazonas, 2010, v. II, p. 272-287.

7. Fernandes, Nelson da Nobrega. Festa, cultura popular e identidade nacional - As Escolas de Samba do Rio de Janeiro (1928-1949). In: Mara da Rosa Correia. (Org.). Oficina de Estudos da Preservação, Coletânea I. Rio de Janeiro: IPHAN-Rio, 2008, v. 1, p. 4-286.

8. Fernandes, Nelson da Nobrega. Onde a cidade perde seu nome. In: Milton Santos et al. (Org.). Territótrio, territórios: ensaios sobre o ordenamento territorial. 3ed.Rio de Janeiro: Lamparina, 2007, v. 1, p. 197208.

9. Fernandes, Nelson da Nobrega. Onde a cidade perde seu nome. In: Milton Santos; Bertha K. Becker. (Org.). Território, territórios: ensaios sobre o ordenamento territorial. Rio de Janeiro: DP\&A, 2006, v., p. 1-416.

10. Fernandes, Nelson da Nobrega. Sentido espacial da renda da terra e espaço urbano. In: Ruy Moreira. (Org.). Geografia. Teoria e crítica. Petrópolis: Vozes, 1982, v., p. 112-119.

\section{Textos em jornais de notícias/revistas}

1. Fernandes, Nelson da Nobrega. Urbanização militar e origens da habitação social no Brasil. GeocritiQ Plataforma digital ibero-americana para la difusión del trabajo científico, Barcelona, 30 nov. 2013.

2. Fernandes, Nelson da Nobrega. Brasil se levanta por el derecho a la ciudadania. La veu del carrer, Barcelona, p. 10 - 10, 25 set. 2013. 


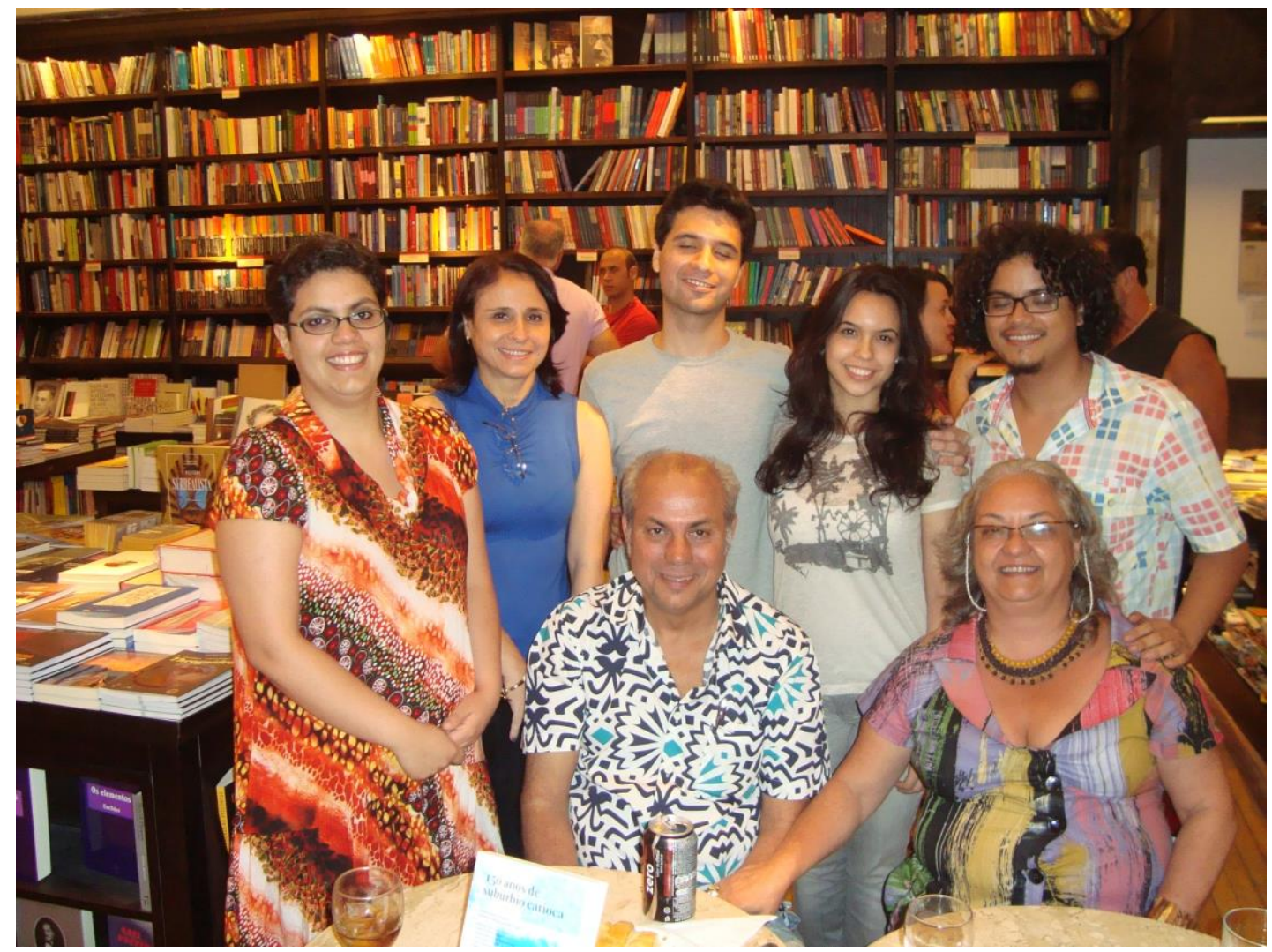

Lançamento do livro 150 Anos de Subúrbio Carioca, em 30/11/2010. Foto: Arquivo da família 